\title{
BMJ Open Physical activity as intervention for age-related loss of muscle mass and function: protocol for a randomised controlled trial (the LISA study)
}

\author{
Christian Skou Eriksen, ${ }^{1,2}$ Ellen Garde, ${ }^{2,3,4}$ Nina Linde Reislev, ${ }^{2,3}$ \\ Cathrine Lawaetz Wimmelmann, ${ }^{2,4}$ Theresa Bieler, ${ }^{1,2,5}$ Andreas Kraag Ziegler, ${ }^{1,2}$ \\ Anne Theil Gylling, ${ }^{1,2}$ Kasper Juel Dideriksen, ${ }^{1,2}$ Hartwig Roman Siebner, ${ }^{3,6}$ \\ Erik Lykke Mortensen, ${ }^{2,4}$ Michael Kjaer ${ }^{1,2}$
}

To cite: Eriksen CS, Garde E, Reislev NL, et al. Physical activity as intervention for age-related loss of muscle mass and function: protocol for a randomised controlled trial (the LISA study). BMJ Open 2016;6: 012951 . doi:10.1136/bmjopen-2016012951

- Prepublication history for this paper is available online To view these files please visit the journal online (http://dx.doi.org/10.1136/ bmjopen-2016-012951).

Received 7 June 2016 Revised 4 October 2016 Accepted 8 November 2016

CrossMark

For numbered affiliations see end of article.

Correspondence to

Christian Eriksen;

eriksen.christian@gmail.com

\section{ABSTRACT}

Introduction: Physical and cognitive function decline with age, accelerating during the 6th decade. Loss of muscle power (forcexvelocity product) is a dominant physical determinant for loss of functional ability, especially if the lower extremities are affected. Muscle strength training is known to maintain or even improve muscle power as well as physical function in older adults, but the optimal type of training for beneficial long-term training effects over several years is unknown. Moreover, the impact of muscle strength training on cognitive function and brain structure remains speculative. The primary aim of this randomised controlled trial is to compare the efficacy of two different 1 year strength training regimens on immediate and long-lasting improvements in muscle power in retirement-age individuals. Secondary aims are to evaluate the effect on muscle strength, muscle mass, physical and cognitive function, mental wellbeing, health-related quality of life and brain morphology.

Methods and analysis: The study includes 450 home-dwelling men and women (62-70 years). Participants are randomly allocated to (1) 1 year of supervised, centre-based heavy resistance training, (2) home-based moderate intensity resistance training or (3) habitual physical activity (control). Changes in primary (leg extensor power) and secondary outcomes are analysed according to the intention to treat principle and per protocol at 1, 2, 4, 7 and 10 years.

Ethics and dissemination: The study is expected to generate new insights into training-induced promotion of functional ability and independency after retirement and will help to formulate national recommendations regarding physical activity schemes for the growing population of older individuals in western societies. Results will be published in scientific peer-reviewed journals, in $\mathrm{PhD}$ theses and at public meetings. The study is approved by the Regional Ethical Committee (Capital Region, Copenhagen, Denmark, number H-32014-017).

Trial registration number: NCT02123641.

\section{Strengths and limitations of this study}

- The LIve active Successful Ageing (LISA) study is the first randomised and supervised 1 year strength training study performed on older adults close to retirement age with a planned long-term follow-up period (2, 4, 7 and 10 years).

- We include a relatively large cohort (450), which makes it possible to detect even smaller significant changes on a large battery of important health-related physical, cognitive and mental outcomes.

- Men and women, healthy and those with a certain degree of chronic diseases, are allowed to participate, which strengthens the external validity of the study but at the same time may introduce a larger variation in the results.

- Detailed analyses at the molecular level are not carried out, but subgroup studies of more mechanistic, invasive nature are allowed after approval by the ethical committee and the project steering group.

\section{BACKGROUND}

Physical inactivity and high age are associated with increased mortality and morbidity in humans. ${ }^{1-3}$ A significant proportion of older adults do not meet the physical activity recommendations required to reduce morbidity and maintain functional ability. ${ }^{4} 5$ Skeletal muscle mass and strength decline gradually by $2 \%$ each year from the sixth decade $^{6}$ adversely affecting activities of daily living in $30 \%$ of all individuals over the age of $70 .{ }^{6-10}$ Importantly, there is an even more pronounced age-related loss of muscle power (muscle forcexvelocity product), declining by $3-3.5 \%$ each year from the age of 50-60 years, ${ }^{11}$ which is known to be more closely 
associated with the decline in functional ability than the mere loss of muscle mass and strength. ${ }^{11-14}$

Several factors influence the age-related loss of muscle function, but especially a gradual decline in physical activity observed in older adults appears to be important. ${ }^{715}$ Additionally, acute reductions of physical activity in older individuals can accelerate the age-related decline in muscle mass and function. Immobilisation, due to bed rest or hospitalisation, results in a very fast and pronounced loss of muscle power $(14 \%$ in 10 days), ${ }^{16}$ and muscle mass (4-6 days), which is only slowly and insufficiently regained during rehabilitation. ${ }^{17}$

Transitions in life circumstances such as retirement pose a challenge to many people and may change the pattern of physical activity. ${ }^{18-20}$ Studies investigating the actual changes in physical activity level after retirement have shown inconsistent results. ${ }^{21-24}$ The inconsistency may be related to differences in socioeconomic status and previous profession, which are known to influence physical activity after retirement. ${ }^{25-29}$ Little is known about individual factors influencing physical activity after retirement, but individual personality traits may have impact on the level of physical activity. ${ }^{30}$

Systematic reviews of exercise interventions for promoting physical activity level in middle-aged to elderly individuals have shown moderate effects over 612 months of intervention, ${ }^{31}{ }^{32}$ whereas knowledge about longer lasting ( $>12$ months) effects is sparse. A meta-analysis of training studies performed on 5570 year old individuals demonstrated good effect of physical activity and lifestyle interventions on physical activity level at termination of 12 months intervention, ${ }^{33}$ but it was unclear whether this effect lasted beyond the intervention. Only 1 of 15 trials in the meta-analysis used an accelerometer as assessment tool, and that study could not demonstrate any increase in daily activity after 12 months training, ${ }^{34}$ or at a 12 -month postintervention follow-up. To date, no exercise intervention has thus proven to be effectively increasing or maintaining a high daily physical activity level beyond the intervention period.

Supervised centre-based heavy resistance exercise has proven to be effective with regard to increasing muscle mass and strength in healthy older adults ${ }^{35}$ as well as in patients with osteoarthritis ${ }^{36}$ and to reduce physical limitations. ${ }^{37}$ However, training-related discomfort and side-effects such as injuries may increase the risk of participants dropping out of the study. In fact, it has been shown that after termination of a supervised training intervention of 2-3 months only few people continue this type of training. ${ }^{38-40}$ Resistance training at moderate intensity, targeting only $60 \%$ of one repetition maximum has shown to increase muscle protein synthesis in older individuals and this metabolic parameter, which mediates muscle hypertrophy, seems to be more dependent on training volume than on training intensity per se. ${ }^{41}{ }^{42}$ Improvement in muscle power may also be obtained at lower training loads but with a higher velocity of contraction. ${ }^{43} 44$ Thus, moderate intensity types of exercise may lead to gains in muscle mass as well as muscle power and overall function in older individuals that are comparable to classic heavy resistance training (HRT). Whether such improvements are maintained over several years remains to be investigated in a long-term follow-up study.

Physical activity in retirement-aged individuals has been associated with improvements in several mental characteristics including cognition, ${ }^{45}{ }^{46}$ depressive states $^{47} 48$ and health-related quality of life. ${ }^{49} \mathrm{~A}$ randomised study ${ }^{50}$ reported that two types of training programmes (strength and flexibility exercise) both had positive effects on different aspects of functioning and mental well-being in individuals aged 65 years or older. For both training programmes, individuals showed better adherence to the home-based training sessions compared with the class-based sessions. Thus, it is possible that individuals at retirement-age are more prone to implement and adhere to exercise in their daily lives after a home-based moderate intensity training intervention with periodic supervision than after a centre-based HRT intervention, but this remains to be compared directly in a long-term follow-up study.

Like the muscles, the brain is subject to age-related atrophy, resulting in shrinkage of brain volume, decrease in cortical thickness, surface area and gyrification, as well as increase in ventricular volume. ${ }^{51}{ }^{52}$ Changes in white matter microstructure are accelerating from the sixth decade ${ }^{53}$ affecting the integrity of the white matter connections, disrupting neural integration in functional brain networks ${ }^{54}$ and affecting cognitive function. ${ }^{55} 56$ Although a recent meta-analysis did not find evidence that cognitive function benefit from aerobic physical activities several studies have shown that regular physical activity increases plasticity of the brain ${ }^{57} 58$ and has beneficial effects on brain structure and function, ${ }^{45} 5960$ which parallel improvement in muscle structure and physical function. ${ }^{61}$

Ageing is associated with accumulation of cardiovascular risk factors impairing cerebral vascular and metabolic functions. ${ }^{62}$ Physically fit older adults have been shown to have lower blood pressures and higher cerebrovascular reserve. ${ }^{45} 6364$ A recent study supports the notion that cardiovascular exercise may be an efficient way to modulate vascular changes and improve cognitive health in later life ${ }^{65}$ potentially mediated through higher levels of white matter microstructural organisation. ${ }^{66}$ Yet it still remains to be clarified whether training at retirement-age exerts long-lasting beneficial effects on brain structure and function and if so, which type of training is effectively delaying or even preventing age-related cognitive decline.

\section{AIMS}

The LIve active Successful Ageing (LISA) study is a cross-disciplinary approach to ageing research aiming to 
understand and find ways to delay or even reverse the age-related decline of physical and cognitive function. The primary aim is to compare the immediate and longterm (2-10 years) efficacy of two different 1 year resistance training interventions (high intensity vs moderate intensity) with a non-exercising control group in moderately old individuals close to retirement-age (6270 years) on the following outcomes:

1. Primary outcome: leg extensor power.

2. Secondary outcomes: muscle strength, muscle mass, functional ability, daily level of physical activity, health-related quality of life, mental distress, personality, adherence to training, cognitive ability, MRI brain imaging parameters.

\section{HYPOTHESES}

The trial evaluates the following hypotheses:

1. Compared to a control group, 1 year of heavy or moderate intensity resistance training improves leg extensor power. HRT is superior to moderate intensity resistance training with respect to improvements in muscle power.

2. In long-term follow-ups (2-10 years), moderate intensity training is associated with higher general physical activity level and is comparable or even superior to high intensity resistance training with respect to maintenance of muscle power, muscle strength, muscle mass and functional ability.

3. Compared to a control group, both training interventions are associated with immediate and long-term increase in quality of life and a decrease in mental distress.

4. Compared to a control group, both training interventions are associated with greater hippocampal and prefrontal cortex volumes.

5. Higher $400 \mathrm{~m}$ walking performance is at all time points associated with higher levels of white matter microstructural organisation (fractional anisotropy, FA).

6. Cognitive ability and personality predict short-term and long-term adherence to intervention programmes and changes in physical activity level.

7. Irrespective of intervention type, follow-up measures of quality of life, mental distress, cognitive ability and changes on MRI scans are associated with the amount of physical activity.

\section{METHODS}

\section{Study design}

The LISA study is an efficacy study and will be conducted as a single-blinded (outcome assessors) single centre, multidisciplinary, randomised controlled trial with a parallel group design. The data collection is administered by the Institute of Sport Medicine Copenhagen, Bispebjerg Hospital, in collaboration with the Department of Public Health, Section of Environmental Health, University of Copenhagen and Danish Research
Centre for Magnetic Resonance, Hvidovre Hospital, Copenhagen, Denmark. The study protocol adheres to the Standard Protocol Items: Recommendations for Interventional Trials (SPIRIT) guidelines for clinical trial protocols. ${ }^{67}$ After baseline assessment, participants will be randomised to 12 months of either heavy or moderate intensity resistance training or habitual physical activity level $(<1$ hour of systematic strenuous physical activity/week (control group)). Assessments are carried out at baseline, 1, 2, 4, 7 and 10 years, where primary (leg extensor power) as well as secondary outcomes will be analysed according to the intention to treat principle and per protocol. A study flow chart is presented in figure 1 .

\section{Participants}

The study includes 450 home dwelling, independent men and women, 62-70 years of age, living in the greater Copenhagen area. Recruitment was started in April 2014 and is expected to be completed in May 2017. Participants are recruited via advertising in local newspapers, informative media and web-based (http:// www.forsøgsperson.dk). Interested citizens contact (email or telephone) the investigator, who gives information about the study and screen for inclusion and exclusion criteria. If criteria for participation are satisfied, written and oral information are provided, a declaration of informed consent is signed, and dates for the first test days are agreed on (figure 1). Exclusion criteria are: $>1$ hour systematic strenuous exercise a week or regular strength training, severe or dysregulated medical disease (ie, active cancer, uncontrolled diabetes, severe pulmonary or heart disease), musculoskeletal diseases impeding training ability, use of systemic glucocorticoids, androgens or antiandrogens and finally safety concerns in relation to training and MR-scanning.

\section{Randomisation and allocation concealment}

Participants are stratified according to gender (male/ female), functional ability (chair-rise test $\leq 11$ or $>11$ ) and body mass index (BMI $\leq 28$, or BMI $>28$ ) and randomised with a 1:1:1 allocation if they go through all test days without presenting with serious health conditions. Randomisation will be performed according to the order in which participants agree to participate. The computer-generated allocation sequences (one for each case of stratification, $2 \times 2 \times 2=8$ lists) have been provided by an external statistician. Each individual allocation in the sequence has been cut out and concealed in envelopes. The person revealing the allocation is not involved in the recruitment or enrolment of participants. Participants are requested not to reveal their group allocation to the blinded outcome assessors.

\section{Interventions}

Each intervention group conducts a 1 hour whole-body progressive resistance training programme including multiple-joint and single-joint exercises according to 
Figure 1 Flow chart of the LISA study-participants. BMI, body mass index $\left(\mathrm{kg} / \mathrm{m}^{2}\right)$; HRT, heavy resistance training; $\mathrm{MIT}$, moderate intensity training.

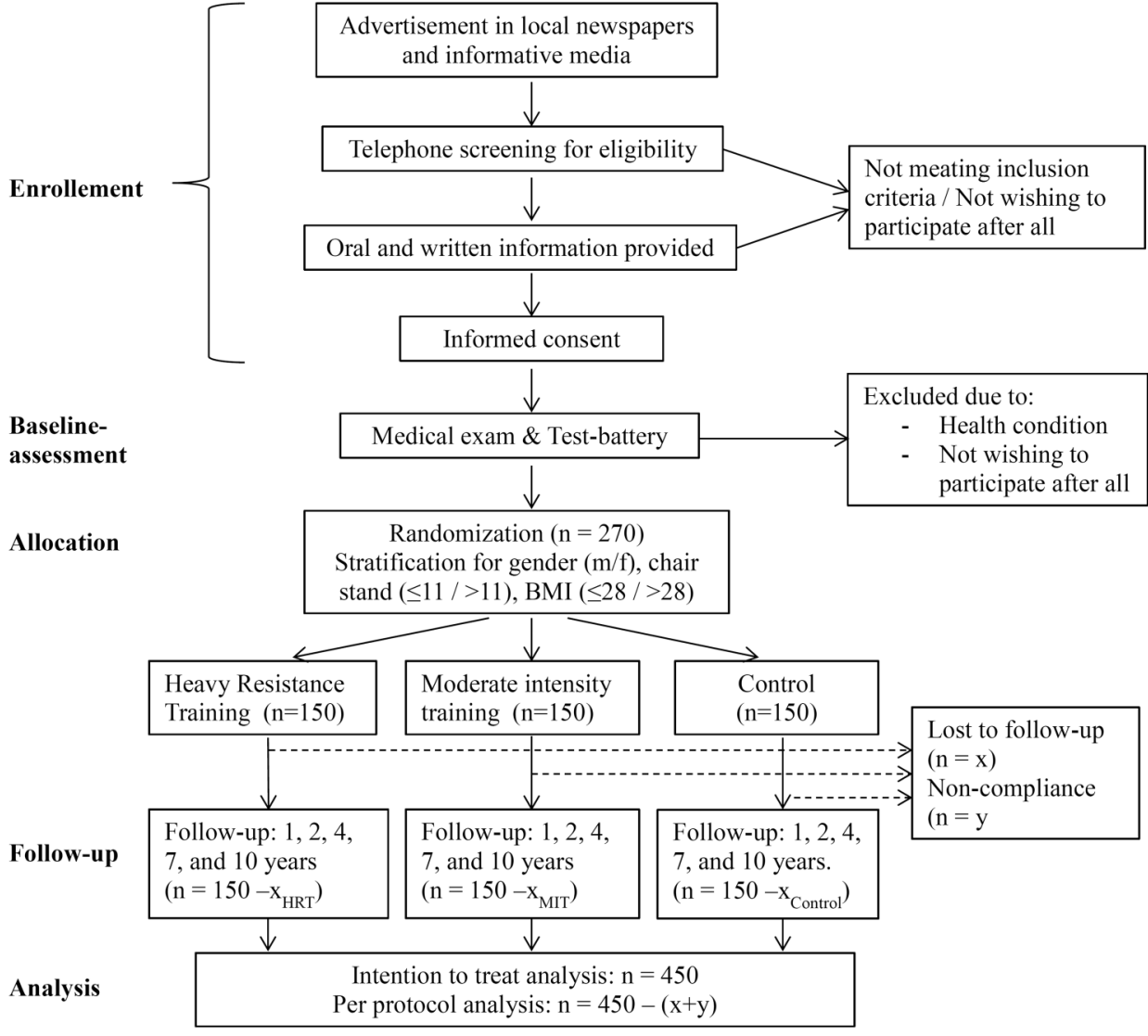

guidelines to resistance training of older adults from the American College of Sports Medicine ${ }^{68}$ with at least 48 hours between training sessions (see table 1 for details). Both training interventions are initiated with a 6-8 week acclimation period at low intensity to reduce the risk of injury and to familiarise the participants to resistance training. Experienced physical trainers supervise the HRT training three times weekly and the MIT training once weekly. Trainers are calibrated regularly to ensure standardisation and optimisation of exercise quality and load progression over time and between the different trainers. All training sessions are registered in training diaries, where participants will register training days, load as well as number of repetitions and sets for each exercise. Participants are strongly encouraged to report any deviations from the intended training programme.

The control group participants are not offered or encouraged to physical activities, but are expected to continue with their habitual physical activity level ( $<1$ hour of regular strenuous physical activity/week). The participants are offered social/cultural activities in order to account for the impact of social activity on health and isolate the possible changes due to the training intervention. Social/cultural activities comprise lectures about ageing and health, guided tours on museums or historical buildings/sites, card clubs and book clubs. Activities will be offered approximately two times a month, and participation is registered by the study staff.

\section{Measurements}

All participants go through a wide range of tests on three separate days before and after the 1 year intervention as outlined in figure 2. Additional follow-up testing is performed at 2, 4, 7 and 10 years after the start of the intervention and comprises the same battery of tests (table 2). Test procedures are audited regularly by experienced and skilled study staff to ensure standardisation of the procedures. Subgroups of the participants are asked to go through additional and more comprehensive testing after approvement by the regional ethics committee and the project steering group.

\section{Medical examination and anthropometrics}

A medical doctor (the study physician) performs a general health screening programme comprising medical history, measurement of height and weight (light clothing, shoes removed), waist circumference (triplet measurement, between iliac crest and ribs, midaxillary) ${ }^{70}$ auscultation of heart and lungs, pulse and blood pressure (sitting) as well as fasting blood samples (sodium, potassium, creatinine, estimated glomerular filtration rate, iron, ferritin, haemoglobin, leucocyte s, thrombocytes, alanine-aminotransferase, alkaline phosphatase, creatine kinase, total cholesterol, HDL-C, LDL-C, VLDL-C, triglycerides, 
Table 1 Overview of the two training interventions

\begin{tabular}{|c|c|c|}
\hline & HRT & MIT \\
\hline \multirow[t]{2}{*}{ Exercises } & $\begin{array}{l}\text { Leg-press, chest-press, knee-extensions, low } \\
\text { rowing, leg-curl, ankle plantar flexion, } \\
\text { hip-abduction. }\end{array}$ & $\begin{array}{l}\text { Squats, push-ups, seated knee-extensions, seated } \\
\text { low rowing, standing hip-abduction and } \\
\text { hip-extension, heel raises. }\end{array}$ \\
\hline & Abdominal crunches and lower back exercises* & Abdominal crunches and lower back exercises* \\
\hline Equipment & Exercise machines (Technogym, Cesena, Italy) & $\begin{array}{l}\text { Elastic exercise bands, } 30 \text { and } 90 \mathrm{~cm} \text { loops (Thera } \\
\text { Band, Akron, Ohio, USA). Own body weight. }\end{array}$ \\
\hline Intensity & $6-12$ rep ( $70-85 \%$ of $1 \mathrm{RM} \dagger)$ & $10-18$ rep $(\sim 50-60 \%$ of $1 \mathrm{RM}+)$ \\
\hline $\begin{array}{l}\text { Rest between } \\
\text { sets }\end{array}$ & $1-2 \min$ & $\begin{array}{l}\text { Circuit training: All exercises are performed once } \\
\text { and the 'circuit' is repeated three times. No rest } \\
\text { between exercises }\end{array}$ \\
\hline $\begin{array}{l}\text { Contraction } \\
\text { velocity }\end{array}$ & $2 \mathrm{~s}$ concentric, $2 \mathrm{~s}$ eccentric & $\begin{array}{l}2 \mathrm{~s} \text { concentric } 2 \mathrm{~s} \text { eccentric except for push-ups, } \\
\text { squats and heel raises that are } 1 \mathrm{~s} \text { concentric and } \\
3 \mathrm{~s} \text { eccentric }\end{array}$ \\
\hline \multirow[t]{4}{*}{ Acclimatisation } & $6-8$ weeks & $6-8$ weeks \\
\hline & Week $1: 1$ set of 15 rep & Week 1: 1 round of 10 rep \\
\hline & Week $2: 2$ sets of 15 rep & Week $2: 2$ rounds of 10 rep \\
\hline & Week 3-8: 3 sets of 15 rep & Week 3-8: 3 rounds of $10-18$ rep \\
\hline \multirow[t]{9}{*}{ Progression } & From week 7-9: & From week 7-9: \\
\hline & Periodisation regimen: & 3 rounds of $10-18$ rep. A gradual increase from 3 \\
\hline & 2 weeks of $3 \times 12$ rep ( $70 \% 1 \mathrm{RM})$ & rounds of 10 to 3 rounds of 18 rep. The last rep \\
\hline & 2 weeks of $3 \times 10$ rep $(\sim 75 \% 1 \mathrm{RM})$ & should feel exhaustive. Training load increases by \\
\hline & 2 weeks of $3 \times 8$ rep $(\sim 80 \% 1 \mathrm{RM})$ & using a stronger elastic band (red $\rightarrow$ green $\rightarrow$ blue \\
\hline & 2 weeks of $3 \times 6$ rep ( $\sim 85 \% 1 \mathrm{RM})$ & $\rightarrow$ black $\rightarrow$ silver $\rightarrow$ gold) except for (1) push-ups \\
\hline & 1 week of restitution & where load increases by gradually decreasing the \\
\hline & The period is repeated. & angle of the body relative to the floor, (2) squats \\
\hline & $\begin{array}{l}\text { Training load is increased when the individual can } \\
\text { do more repetitions than the number specified in } \\
\text { the training protocol above }\end{array}$ & $\begin{array}{l}\text { where load increases by putting one foot on a stool } \\
\text { ( } 5-10 \mathrm{~cm} \text { high) and thereby gradually loading the } \\
\text { foot on the floor more and (3) heel raises where load } \\
\text { increases by changing from a bilateral to unilateral } \\
\text { performance and finally by using weight vests } \\
\text { (adding } 5-10 \% \text { of the body weight) in (1), (2) and } \\
\text { (3). }\end{array}$ \\
\hline Organisation & Groups of 4 & Groups of 8 \\
\hline \multirow[t]{2}{*}{ Location } & Private fitness centre (paid by the project) & Hospital once a week \\
\hline & & At home two times a week \\
\hline \multirow[t]{2}{*}{ Supervision } & Three times weekly & Once a week \\
\hline & & At home two times a week. \\
\hline
\end{tabular}

${ }^{*}$ Abdominal crunches and lower back exercises are included in the training programme to strengthen the core region. Three sets of 15 repetitions are performed at the end of each training session. They do not follow the periodisation regimen, but difficulty is continuously adjusted by skilled physical trainers.

†A 1RM test is not performed but relative intensity in \% 1RM is estimated according to Brzycki. ${ }^{69}$ Participants are told that the last repetitions should feel exhaustive.

HRT, heavy resistance training; MIT, moderate intensity training; Rep, repetitions; RM, repetition maximum; S, seconds.

haemoglobin A1c, thyroid stimulating hormone, C reactive protein).

\section{Perceived age}

Side and front view whole-body photographs as well as face photographs are taken of all participants wearing their normal clothes. Photographs are taken from a distance of $0.6 \mathrm{~m}$ (face) and $3.3 \mathrm{~m}$ (whole body) at a horizontal angle. Perceived age is assessed by blinded assessors according to the methods used previously by Christensen et $a l^{71}$

\section{Physical activity measurement}

On the first test-day an accelerometer/inclinometer (activPal micro, PAL technologies, Glasgow, Scotland) is mounted on the thigh of the dominant leg ('the leg that you most likely would use to kick a football') to measure daily activity level. The accelerometer/inclinometer is worn continuously for five consecutive days, always including the weekend and 3 week days. Daily step count and time spend in motion, standing and sitting/supine position is calculated as the mean of these 5 days. Data are extracted to Excel (Microsoft) with ActivPal software (Research edition, V.7.2.32, PAL Technologies, 2013). 
Figure 2 Overview of measurements on the three test days. All test days are repeated after 1 year intervention.

Overview of assessments at 2, 4, 7 and 10 years are presented in table 1 . Test-day 2 will be carried out between 4 and 7 days after the last training bout at the 1 year follow-up.

\begin{tabular}{|c|c|c|}
\hline $\begin{array}{l}\text { Subjects meet fasting from } \\
10 \mathrm{pm} \text { the day before. They } \\
\text { are allowed to drink water } \\
\text { in the morning. }\end{array}$ & $\begin{array}{l}\text { No less than } 6 \text { and no more } \\
\text { than } 21 \text { days after day } 1 . \\
\text { Subjects are asked to refrain } \\
\text { from strenous physical activity } \\
\text { for the preceding } 72 \text { hours. }\end{array}$ & $\begin{array}{l}\text { Carried out more than } 72 \\
\text { hours after day } 2 \text {. Subjects } \\
\text { are asked to refrain from } \\
\text { strenous physical activity } \\
\text { for the preceding } 72 \text { hours. }\end{array}$ \\
\hline
\end{tabular}

- Medical exam

- Blood samples

- Anthropometrics

- Photografies

- Accelerometer

- Questionnaires
- MRi of the brain

- MRi of both thighs
- Cognitive test

- Physical tests

- Returning accelerometer

- Returning questionnaires

Table 2 Overview of measurements and time points

\begin{tabular}{|c|c|c|c|c|c|c|c|c|}
\hline \multirow[b]{2}{*}{ Measurement } & \multirow[b]{2}{*}{ Device } & \multirow[b]{2}{*}{ Unit } & \multicolumn{6}{|c|}{ Time points } \\
\hline & & & Baseline & 1 year & 2 year & 4 year & 7 year & 10 year \\
\hline \multicolumn{9}{|l|}{ Primary outcome } \\
\hline Leg extensor power & Power rig & Watt & $x$ & $x$ & $x$ & $x$ & $x$ & $x$ \\
\hline \multicolumn{9}{|l|}{ Secondary outcomes } \\
\hline M. vastus lateralis CSA & MRI & $\mathrm{mm}^{2}$ & $x$ & $x$ & $x$ & $x$ & $x$ & $x$ \\
\hline 400 m gait speed & $20 \mathrm{~m}$ track & s & $x$ & $x$ & $x$ & $x$ & $x$ & $\mathrm{X}$ \\
\hline 30s chair stand & Chair & No in 30 s & $x$ & $x$ & $x$ & $x$ & $x$ & $\mathrm{X}$ \\
\hline $\begin{array}{l}\text { Isometric hand grip } \\
\text { strength }\end{array}$ & Dynamometer & $\mathrm{kg}$ & $x$ & $x$ & $x$ & $x$ & $x$ & $x$ \\
\hline Isometric m.q. strength & Good strength & $\mathrm{Nm}$ & $x$ & $x$ & $x$ & $x$ & $x$ & $\mathrm{X}$ \\
\hline Fat percentage & DEXA & $\%$ & $x$ & $x$ & $x$ & $x$ & $x$ & $x$ \\
\hline Muscle mass & DEXA & $\mathrm{kg}$ & $x$ & $x$ & $x$ & $x$ & $x$ & $x$ \\
\hline Bone mineral density & DEXA & $\mathrm{g} / \mathrm{mm}^{2}$ & $x$ & $x$ & $x$ & $x$ & $x$ & $\mathrm{X}$ \\
\hline \multirow[t]{2}{*}{ Physical activity level } & ActivPal & Step-cont & $x$ & $x$ & $x$ & $x$ & $x$ & $x$ \\
\hline & $\begin{array}{l}\text { PASE } \\
\text { Questionnaire }\end{array}$ & $\begin{array}{l}\text { See text for } \\
\text { details }\end{array}$ & $x$ & $x$ & $x$ & $x$ & $x$ & $x$ \\
\hline Percieved age & Photographs & Years & $x$ & $x$ & $x$ & $x$ & $x$ & $\mathrm{X}$ \\
\hline Weight & Digital weight & $\mathrm{Kg}$ & $x$ & $x$ & $x$ & $x$ & $x$ & $\mathrm{X}$ \\
\hline Height & Digital altimeter & $\mathrm{cm}$ & $x$ & $x$ & $x$ & $x$ & $x$ & $\mathrm{X}$ \\
\hline Waist circumference & Tape measure & $\mathrm{cm}$ & $x$ & $x$ & $x$ & $x$ & $x$ & $\mathrm{X}$ \\
\hline $\begin{array}{l}\text { Fasting blood samples } \\
\text { (see text for details) }\end{array}$ & $\begin{array}{l}\text { Standard equipment } \\
\text { and assays }\end{array}$ & $\begin{array}{l}\text { Dependent on the } \\
\text { parameter }\end{array}$ & $x$ & $\mathrm{X}$ & $\mathrm{X}$ & $x$ & $\mathrm{X}$ & $x$ \\
\hline $\begin{array}{l}\text { Background and } \\
\text { lifestyle }\end{array}$ & $\begin{array}{l}\text { Modified CAMB } \\
\text { Questionnaire }\end{array}$ & $\begin{array}{l}\text { See text for } \\
\text { details }\end{array}$ & $x$ & $x$ & $x$ & $x$ & $x$ & $x$ \\
\hline Personality & $\begin{array}{l}\text { NEO-FFI } \\
\text { questionnaire }\end{array}$ & $\begin{array}{l}\text { See text for } \\
\text { details }\end{array}$ & $x$ & $\mathrm{X}$ & $x$ & $x$ & $X$ & $X$ \\
\hline Mental distress & $\begin{array}{l}\text { SCL-90 } \\
\text { Questionnaire }\end{array}$ & $\begin{array}{l}\text { See text for } \\
\text { details }\end{array}$ & $\mathrm{X}$ & $\mathrm{X}$ & $X$ & $X$ & $\mathrm{X}$ & $\mathrm{X}$ \\
\hline $\begin{array}{l}\text { Heal-related quality of } \\
\text { life }\end{array}$ & SF-36 Questionnaire & $\begin{array}{l}\text { See text for } \\
\text { details }\end{array}$ & $x$ & $x$ & $x$ & $x$ & $x$ & $x$ \\
\hline Exercise self-efficacy & Questionnaire & $\begin{array}{l}\text { See text for } \\
\text { details }\end{array}$ & $x$ & $x$ & $x$ & $x$ & $x$ & $x$ \\
\hline Attitude to intervention & $\begin{array}{l}\text { AFRIS } \\
\text { Questionnaire }\end{array}$ & $\begin{array}{l}\text { See text for } \\
\text { details }\end{array}$ & $x$ & & & & & \\
\hline $\begin{array}{l}\text { Adherence to } \\
\text { intervention }\end{array}$ & $\begin{array}{l}\text { Adherence } \\
\text { Questionnaire }\end{array}$ & $\begin{array}{l}\text { See text for } \\
\text { details }\end{array}$ & & & $x$ & $x$ & $x$ & $x$ \\
\hline Cognitive ability & $\begin{array}{l}\text { IST-2000-R } \\
\text { Questionnaire }\end{array}$ & $\begin{array}{l}\text { See text for } \\
\text { details }\end{array}$ & $x$ & $x$ & $x$ & $x$ & $x$ & $x$ \\
\hline $\begin{array}{l}\text { Brain structure and } \\
\text { function }\end{array}$ & MRI & $\begin{array}{l}\text { See text for } \\
\text { details }\end{array}$ & $x$ & $\mathrm{X}$ & $\mathrm{X}$ & $x$ & $\mathrm{X}$ & $x$ \\
\hline
\end{tabular}


Body composition and bone mineral density

Body composition and bone mineral density (BMD), g/ $\mathrm{cm}^{2}$, is evaluated with dual energy X-ray absorptiometry (DEXA)-scan (Lunar iDEXA, GE Medical Systems, Madison, Wisconsin, USA) using enCORE software, V.16. A whole-body scan is performed to determine wholebody BMD, fat percentage, total lean body mass and estimation of thigh muscle mass. The latter is determined manually with a region of interest (ROI) defined proximally by a horizontal line drawn laterally from the distal part of the groin and distally by a line drawn horizontally through the medial tibial plateau. ${ }^{72-74}$ Specific scans of the lumbar spine (anterior-posterior) and both femoral necks are performed to determine regional BMD. The average BMD of the lumbar spine (L2-L4) and femoral necks is determined with a ROI automatically generated by the Encore software. Participants are asked to void before the scans and all jewellery, accessories and clothes except underwear and a standard t-shirt are removed prior to the scanning. Scans are performed by non-blinded study-staff, whereas the manual placement of ROI will be performed by a blinded assessor.

\section{Questionnaires}

The following questionnaires are handed out to the participants on the first test-day. Data management and analysis are handled by investigators blinded to group allocation.

\section{Background and lifestyle}

Information about the participants' background and lifestyle is obtained using a short version of the questionnaire developed for the Copenhagen Aging and Midlife Biobank (CAMB). ${ }^{75}$ The short version questionnaire is customised to fit the aims of the LISA study and provides information on the participants' social background, educational background, family relations, lifestyle and physical health status. An adjusted version of the LISA questionnaire is administered at follow-ups.

\section{Personality}

The Danish version of the NEO Five-Factor Inventory $(\mathrm{NEO}-\mathrm{FFI})^{76}$ is used to assess five broad personality dimensions including Neuroticism, Extraversion, Openness, Agreeableness and Conscientiousness. The NEO-FFI is a short version of the NEO PI-R ${ }^{77}$ and comprises 60 items that are answered on a five-point scale ranging from 'strongly agree' to 'strongly disagree'.

\section{Mental distress}

The 'Symptom Checklist' (SCL-90) ${ }^{78} 79$ is a 90 item inventory used to assess a wide range of mental symptoms. For the purpose of the LISA study, a shorter 35 items version is used to assess symptoms on the three subscales of somatisation, depression and anxiety. In addition, the General Severity Index (GSI), indicating number and severity of symptoms, is calculated as the mean item score across the three subscales. Items are scored in a $0-4$ Likert format with higher scores indicating higher symptom load.

\section{Health-related quality of life}

The Short-Form Health Survey (SF-36) ${ }^{80} 81$ is used to assess the participants' health-related quality of life within the last week. The SF-36 consists of 36 items and obtains information on eight aspects of health-related quality of life including physical function, physical role, physical pain, general health, vitality, social function, emotional role and mental health, with the former four subscales contributing to a physical component and the latter four subscales contributing to a mental component. Raw scores are transformed to range from 0 to 100 with 100 reflecting highest level of health-related quality of life.

\section{Physical activity}

The Physical Activity Scale for the Elderly (PASE) ${ }^{82}$ is used to obtain information on self-reported physical activity among the participants. PASE is an instrument developed specifically for individuals aged 65 years or older and measures level of physical activity over a 1-week period. The instrument consists of 12 items assessing three areas of physical activity including leisure-time physical activity, work-related physical activity and household physical activity. On the basis of frequency, duration and intensity level of each area of activity, a total PASE score is derived, which represents the overall activity level with 0 indicating total inactivity.

\section{Exercise self-efficacy}

The Confidence Self-efficacy Scale ${ }^{83}$ is used to measure the participants' self-efficacy with regard to physical activity. Judgements of self-efficacy expectations are thought to play an important role in determining whether an individual performs a given behaviour and the degree of effort the individual invests in the behaviour. ${ }^{84}$ The Confidence Self-efficacy Scale consists of five items assessing how confident the participants are with regard to being physically active in different situations such as 'When I am tired' or 'When I am on vacation'. Physical activity includes activities such as walking briskly, jogging, bicycling, swimming and other activities with a similar level of exertion. Questions are answered on a 5-point scale ranging from 1 ('not at all confident') to 5 ('extremely confident'). The total score is calculated as the sum of the 5 items and range from 5 to 25 with a higher score indicating more exercise self-efficacy.

\section{Attitude to intervention}

The Attitudes to Falls-Related Interventions Scale (AFRIS) ${ }^{85}$ is used to address the participants' attitude to the intervention. The questionnaire is based on the 'Theory of planned behaviour', ${ }^{86}$ which indicates how attitudes and beliefs can predict intentions and behaviour. AFRIS comprises 6 items assessing the core components of 'Theory of planned behaviour' including 
expectations to the objective outcome (item 1), expectations to the subjective experience (item 2), beliefs about the attitude of important others (item 3), perceived behavioural control (item 4), identity (item 5) and intention (item 6). Each item is scored from 1 (disagree strongly) to 6 (agree strongly) and thus the total scale score ranges from 6 to 36 with a higher score indicating a more positive attitude to the intervention.

\section{Adherence}

Currently, there seems to be a lack of consensus on how to assess exercise adherence. ${ }^{87}$ In the present study, adherence is defined as the extent to which the participant has continued the assigned intervention. The adherence measurement tool is a questionnaire developed by the authors specifically for the LISA project. The questionnaire asks about how long the participant has continued the intervention since the last assessment, the weekly frequency of training sessions and the extent to which the participant has performed the same exercises. The questions are answered on a 5-point scale ranging from 'never'/'not at all' to 'all the time'/'more than three times a week', respectively. Participants are also asked to evaluate the contribution of different reasons for continuing or discontinuing the intervention on a 5-point scale ranging from 'did not contribute' / no significance' to 'contributed a lot'/'very significant'. Adherence is also evaluated indirectly by the PASE questionnaire and the ActivPal accelerometer.

\section{Physical testing}

Trained assessors blinded to the allocation and the participants previous test results perform the following physical tests in the same order at baseline and follow-up.

\section{$400 \mathrm{~m}$ walk test}

The $400 \mathrm{~m}$ walk test assesses walking endurance. Time to complete a $400 \mathrm{~m}$ walk on a $20 \mathrm{~m}$ flat course marked with two cones is recorded with a stopwatch. Participants are instructed to complete 10 laps (40 m per lap) 'as quickly as possible' and at the end of each lap, standard encouragement is given, as well as laps remaining (eg, '4 down, 6 to go') ${ }^{88}$ This test has shown excellent reproducibility (ICC $=0.95$ ) in middle-aged healthy women ${ }^{89}$ and to provide a valid estimate of peak $\mathrm{VO}_{2}$ in older adults. ${ }^{88}$

\section{Leg extensor power}

Leg extensor power measurement assesses maximum single leg extensor power (forcexvelocity) expressed in watts measured in a Leg Extensor Power Rig (Queen's Medical Centre, Nottingham University, UK).$^{90}$ In a seated position with hands across the chest the participant is instructed to kick the pedal as hard and fast as possible. A single explosive lower limb extension accelerates a flywheel from rest and the maximum speed of the flywheel is used to calculate an average power of the lower limb extensor muscles. The dominant lower extremity is tested first. After two practice trials, the measurement is repeated until no further improvement occurs, but at least five times. Each trial is separated by a rest period of $20 \mathrm{~s}$. The highest value is used for data analysis. This procedure has shown excellent reproducibility $\quad(\mathrm{ICC}=0.92-0.94 ; \quad \mathrm{CV}=8-10 \%) \quad$ in healthy older adults. ${ }^{90} 91$

\section{0 s Chair stand test}

$30 \mathrm{~s}$ chair stand test assesses functional lower extremity strength and endurance. The score is the number of stands from a straight-back chair without armrest (seat height $44.5 \mathrm{~cm}$ ) completed in $30 \mathrm{~s}$ with hands crossed against the chest. Excellent reproducibility $(\mathrm{ICC}=0.84$ $0.92 ; \mathrm{CV}=9 \%$ ) has previously been demonstrated for this standardised measurement procedure in healthy older adults. ${ }^{91} 92$

\section{Grip strength}

Grip strength assesses maximal isometric hand grip strength expressed in kilogram measured with a SAEHAN DHD-1 Digital Hand Dynamometer (a proxy of upper limb muscle strength). The participant is seated in a straight-back chair with armrest with the arm along the side, the elbow bent at $90^{\circ}$, the forearm resting on the armrest and the wrist placed just over the end of the armrest. The wrist is in a neutral position, and thumb is facing upwards. ${ }^{93}$ The width of the handle is adjusted to fit the hand size. Participants are instructed to squeeze the dynamometer as hard as possible for about $5 \mathrm{~s}$ with standardised verbal encouragement. After a practice trial with the dominant hand and subsequently the non-dominant hand, the measurement will be repeated for each hand alternating sides until no further improvement occurs but at least three times for each hand. The highest value for each hand is used for data analysis. Excellent reliability $(\mathrm{ICC}=0.94)$ has previously been demonstrated for grip strength measurements in healthy older adults. ${ }^{94}$

\section{Quadriceps muscle strength}

Quadriceps muscle strength measurement assesses maximal isometric quadriceps torque expressed in Newton metres measured with the Good Strength device (V.3.14 Bluetooth; Metitur, Finland). The participant is seated in the Good Strength chair with hands across the chest, hips flexed at $90^{\circ}$ and knees flexed at $70^{\circ}$. Stabilisation belts are placed across the waist and distally across the ipsilateral thigh, and the strain gauge transducer is placed $5 \mathrm{~cm}$ above the malleoli. The lever arm is determined as the measured distance from the transducer to the joint axis of rotation. The participants are instructed to perform at their maximum ability and standardised verbal encouragement and visual feedback is given. The dominant lower extremity is tested first. After a practice trial, the measurement is repeated until no further improvement occurs, but at least three times. Each trial is separated by a rest period of $60 \mathrm{~s}$. The highest value is used for data analysis. The procedure 
has shown excellent reproducibility $\quad(\mathrm{ICC}=0.90-0.94$; $\mathrm{CV}=7-8 \%$ ) in healthy older adults. ${ }^{91}$

\section{Cognitive ability}

The 'Intelligence Structure Test 2000 Revised' (IST-2000-R) is an intelligence test battery based on nine subtests. ${ }^{95}$ The Danish version used in the LISA study includes three subtests evaluating the participants' cognitive ability based on Sentence Completion, Verbal Analogies and Number Series. The total IST-2000-R score is defined as the sum of the three subtest scores and has a range from 0 to 59 with higher scores reflecting better cognitive ability. ${ }^{76}$ Data management and analysis are handled by investigators blinded to group allocation.

\section{Magnetic resonance imaging of brain and thigh}

An experienced radiographer blinded to group allocation acquires MRI of the brain and thigh using a $3.0 \mathrm{~T}$ TX Philips Achieva scanner (Philips Healthcare) with a 32-channel head coil and body array coil for the thigh MRI. MRI sequence parameters are outlined in table 3 . The MRI of the brain include 3D T1-weighted, 3D T2-weighted and 3D FLAIR. Lesions are manually drawn on the FLAIR image, based on expert visual examinations of the FLAIR, T2-weighted and T1-weighted images. A six-echo 3D gradient echo sequence is acquired for additional assessment of microbleeds. Ten minutes of resting-state functional MRI (rs-fMRI) is acquired to assess functional connectivity between brain regions at rest, where the participants are instructed to lie still with their eyes open and without falling a sleep. A pulsed-gradient spin-echo diffusion-weighted MRI (DWI) sequence is acquired for the assessment of microstructural features of the normal appearing white matter and lesion tissue as well as assessment of white matter fibre pathways and structural connectivity based on tractography. Finally, arterial spin labelling (ASL) is acquired to assess cerebral blood flow and perfusion of peripheral gray matter tissue and subcortical structures.

MRI of the thighs include a 2D axial T1-weighted sequence acquired at 10,20 and $30 \mathrm{~cm}$ above tibia plateau, with three slices at each level for delineation of vastus lateralis of the quadriceps muscle and calculation of crosssectional area, and a 3D two-point Dixon sequence for measures of a fat/muscle ratio. Lipid spectroscopy is acquired on a subset of the participants as additional exploratory information to the Dixon sequence. Image analysis is conducted by blinded assessors.

\section{Retention}

The study staff makes every effort to ensure that participants comply with and adhere to the randomly prescribed interventions and follow-up assessments. Participants are contacted by telephone if they do not show up for two or more consecutive training sessions. The participants receive a reminder on email $\sim 3$ months in advance of the follow-up assessments and shortly thereafter they receive a telephone call from the study staff to agree on dates for examination and follow-up testing. Finally, an email confirming the dates is sent $\sim 1$ month prior to the first test-day of the follow-up. It is underlined that testing is offered irrespective of the participant's compliance with the prescribed intervention. In case of serious illness or injury, which makes the participant unable to continue training within the predetermined training period of 1 year, participants are offered a consultation with the study physician to evaluate whether or not it is advisable and safe to continue the intervention and the follow-up measurements. Participants who cannot complete the follow-up measurements due to illness or injury are retained in the study for future follow-up measurements.

\section{Table 3 Overview of the MRI sequence parameters in LISA}

\begin{tabular}{|c|c|}
\hline MRI sequence & Parameters \\
\hline \multicolumn{2}{|l|}{ Whole brain } \\
\hline 3D T1-weighted & $\mathrm{TR} / \mathrm{TE}=6 / 2.7 \mathrm{~ms}, \mathrm{FA}=8,288 \times 288$ matrix, 244 slices, isotropic voxels $0.85^{3} \mathrm{~mm}^{3}$. \\
\hline 3D T2-weighted & $\mathrm{TR} / \mathrm{TE}=2500 / 270 \mathrm{~ms}, \mathrm{FA}=90,288 \times 288$ matrix, 224 slices, isotropic voxels $0.85^{3} \mathrm{~mm}^{3}$. \\
\hline 3D FLAIR & $\mathrm{TR} / \mathrm{TE} / \mathrm{Tl}=4800 / 328 / 1650 \mathrm{~ms}, 256 \times 256$ matrix, 202 slices, isotropic voxels $1^{3} \mathrm{~mm}^{3}$. \\
\hline $3 \mathrm{D}$ gradient-echo & $\begin{array}{l}\mathrm{TR}=16 \mathrm{~ms}, \mathrm{FA}=10,240 \times 240 \text { matrix, } 170 \text { slices, } 6 \text { volumes: } \mathrm{TE}_{1-6}=2.4,4.8,7.2,9.5,11.9,14.3 \mathrm{~ms} \text {, } \\
\text { in-plane resolution } 1^{2} \mathrm{~mm}^{2} \text {, slice thickness } 1.2 \mathrm{~mm} \text {. }\end{array}$ \\
\hline Rs-fMRI & $\mathrm{EPI}, \mathrm{TR} / \mathrm{TE}=2490 / 30 \mathrm{~ms}, 64 \times 64$ matrix, 42 slices, 240 volumes, isotropic voxels $3^{3} \mathrm{~mm}^{3}$. \\
\hline DWI & $\begin{array}{l}\text { EPI with SENSE factor } 2,62 \text { uniformly distributed directions with } b=1000 \mathrm{~s} / \mathrm{mm}^{2} \text { and } 1 b=0 \mathrm{~s} / \mathrm{mm}^{2} \text {, } \\
\text { TR/TE=8028/88 ms, } 112 \times 112 \text { matrix, } 66 \text { slices, isotropic voxels } 2^{3} \mathrm{~mm}^{3} \text {. }\end{array}$ \\
\hline ASL & $\begin{array}{l}\text { EPI with SENSE factor } 2.5, T R / T E=4610 / 13 \mathrm{~ms}, 80 \times 80 \text { matrix, } 22 \text { slices, } 90 \text { volumes, in-plane } \\
\text { resolution } 3^{2} \mathrm{~mm}^{2} \text {, slice thickness } 6 \mathrm{~mm} \text {, tag duration }=1800 \mathrm{~ms} \text {, tag delay }=2000 \mathrm{~ms} \text {. } \\
\text { M0 reference volume: TR/TE }=9000 / 13 \mathrm{~ms}, 22 \text { slices. }\end{array}$ \\
\hline \multicolumn{2}{|r|}{ (1) } \\
\hline $\begin{array}{l}\text { 2D T1-weighted } \\
\text { axial }\end{array}$ & $\begin{array}{l}\text { TR/TE=666/20 ms, FA=90, } 672 \times 672 \text { matrix, } 3 \text { stacks with } 3 \text { slices, gap } 1.91 \mathrm{~mm} \text {, in-plane resolution } \\
0.8^{2} \mathrm{~mm}^{2} \text {, slice thickness } 4 \mathrm{~mm}\end{array}$ \\
\hline 3D mDixon & $\mathrm{TR}=5 \mathrm{~ms}, \mathrm{TE}_{1-2}: 2.3,3.4 \mathrm{~ms}, 288 \times 288$ matrix, 260 slices, isotropic voxels $1.5^{3} \mathrm{~mm}^{3}$. \\
\hline
\end{tabular}




\section{Statistical considerations}

The LISA study compares two intervention groups with a control group giving three possible comparisons (HRT vs control, MIT vs control and HRT vs MIT). When estimating sample size, we wished to be able to detect an overall group difference in leg extensor power changes based on one-way analysis of variance (ANOVA) and also to detect differences in post hoc pairwise group comparisons. We chose a power level of $80 \%$ and a significance level of 0.05 for the ANOVA model and a Bonferroni corrected significance level of $0.05 / 3=0.016$ for the pairwise comparisons. On the basis of previous research, ${ }^{44} 96-99$ we expected a realistic $10 \%$ difference in the improvements in leg extensor power between groups at 1 year (ie, control group: 175-184 w (+5\%), MIT: 175-202 w (10\% more than control), HRT: 175-222 (10\% more than MIT)). A recent meta-analysis supported this, since they found a $10 \%$ increase in leg extensor power to be clinically relevant at least in mobility-limited older adults. ${ }^{100}$ With an estimated SD of the improvement in leg extensor power of 30, we needed 60 participants in each group to detect pairwise group differences of $10 \%$. We have chosen to include 150 participants in each group, which will enable us to detect smaller groups differences and larger variations in secondary outcomes. Further, with an estimated loss to follow-up of $50 \%$ over a 10 -year period, we will still be able to detect a $10 \%$ group difference in the per protocol analysis of the primary outcome.

Descriptive statistics of baseline data will be presented as means \pm SDs. Changes in the primary outcome (leg extensor power) at 12 months will be compared between groups using one-way ANOVA with post hoc pairwise comparisons. The intention to treat principle will be applied, and advanced multiple imputation techniques will be used to account for missing data. Secondary outcomes will be analysed by appropriate statistical tests depending on the nature of the specific outcome measure.

\section{Risks, disadvantages and adverse events}

The disadvantages and risk of adverse events in the present study are considered low. Blood samples are drawn from the antecubital vein after disinfection with alcohol swabs. There is a minimal risk of infection and bleeding related to the procedure. In relation to training, there is a risk of developing delayed onset muscle soreness (DOMS) following training, ${ }^{101}$ especially in the beginning of the intervention. DOMS can be uncomfortable, but is entirely safe and diminishes after acclimatisation to training.

There is a small risk of injury related to both resistance training interventions. Pain or discomfort in relation to the HRT or MIT exercises is initially dealt with by adjusting the exercise or training volume and intensity. In cases of acute injury or persistent symptoms of overload, participants are offered a consultation with an experienced sports physician (orthopaedic surgeon or rheumatologist) at the Institute of Sports Medicine
Copenhagen. Pausation, temporary adjustment of exercises or discontinuation of the intervention is decided in collaboration between the physician, study staff and the participant and will be reported. Physical testing is not considered to pose the participant at risk of adverse events or discomfort.

DEXA-scans performed at baseline and 12 months follow-up expose the individual to a radiation dose of maximally $0.88 \mathrm{mSv}$, which corresponds to a stochastic risk of 1/100.000 (IRCP-category IIa) of developing a cancer due to the radiation.

There are no known side-effects to MRI, but the procedure can be uncomfortable. A thorough anamnesis is carried out before the examination to account for contraindications (ie, metal implants that can cause magnetic field interactions, heatings and induced currents). Unexpected findings which may have health implications for the participant will be dealt with according to local hospital guidelines.

\section{Storage of personal information}

The identities of all participants are known and will be registered and stored separately from the analysis databases. Data will be anonymised in all publications. Patient data are protected in accordance with the Danish Act on the Processing of Personal Data and Danish Health Act. The Danish Data Protection Agency has approved the project.

\section{Dissemination}

Results from the study will be published, independent of the nature of the results, in scientific peer-reviewed journals, in $\mathrm{PhD}$ theses and at public meetings in relation to the final findings of the project. Data will be published on http://www.clinicalstudyresult.org in case the results are not accepted by a scientific peer-reviewed journal. Any changes or additions to the protocol will be registered on clinicaltrials.gov. Authorship will be granted only to those who fulfil the authorship criteria recommended by the International Committee of Medical Journal Editors.

\section{DISCUSSION}

The LISA study is to the best of our knowledge the first RCT with a planned long-term follow-up period (210 years) comparing the efficacy of two different intensities of resistance training on physical and cognitive function in a retirement-aged (62-70 years) population including healthy persons as well as individuals with some degree of chronic disease. Muscle power has been chosen as the primary outcome because this measure validly reflects physical function in older adults. ${ }^{11}$ Secondary outcomes will contribute with detailed knowledge about the influence of resistance training on changes in physical and cognitive function as well as health-related quality of life, mental well-being, body composition and brain morphology with ageing. 
From April 2014 to March 2016, we have included and randomised 270 participants $(38 / 62 \%$ men/women) to the three experimental groups. Initial contact has been taken to a total of 571 individuals giving an inclusion rate of $47 \%$. Of the 571 individuals, $24 \%$ (135) had one or more exclusion criteria, $23 \%$ (131) did not have the time due to work, travelling or other personal interests and another $6 \%$ (35) declined participation after receiving detailed project information. The main reason for exclusion has been more than one hour of systematic strenuous physical activity per week, whereas only about $3 \%$ of the contacted individuals have been excluded due to medical reasons. The main reasons for declining to participate after receiving detailed information about the project is 'not having the time or energy to participate' or 'only wanting to participate in one or two of the intervention groups'. Only $1 \%(5)$ of the contacted individuals have declined to participate due to the nature of the assessments. As of March 2016, 110 participants have been invited to 12 month follow-up, and only 7\% (8) of these have decided to drop out of the study. Two-year follow-up is planned to begin in June 2016, and we expect to enrol the last participants in May 2017.

The LISA study includes healthy individuals as well as people with some degree of chronic disease. We believe that this approach strengthens the external validity of the study, since the study population, though more heterogeneous, also is more representative of the background population compared to studies with more narrow inclusion criteria. In spite of our effort to closely represent the background population, we are limited by the fact that the study is conducted at a hospital located in Copenhagen, and most volunteers live in the more wealthy part of Copenhagen and the greater Copenhagen area. Moreover, individuals who are either too sick or not interested or motivated to participate in a training intervention are obviously not represented in the study population, and these two facts introduce a source of selection bias, which is likely to make the study population more healthy than the background population.

We consider participation in the project to be safe, since experienced and carefully trained staff performs all assessments as well as instruction and supervision of exercises. The acclimatisation periods used in the exercise interventions further reduce the risk of injuries, and as of March 2016 injuries directly related to the training protocol have only occurred in 5\% (9) of the participants in the training groups with an even distribution between the MIT (4) and HRT (5) groups. One acute injury has presently occurred when a participant dropped a weight disc on the toe, whereas the most prevalent overload symptom is knee-pain followed by shoulder pain. Adverse events related to data acquisition have not occurred, but discomfort related to the MR scanning is common and acute claustrophobia has occurred in $5 \%$ (14) of the participants.

\section{Perspectives}

Results from the LISA study are expected to lead to national recommendations regarding physical activity for individuals around the age of retirement, which may prevent or postpone age-related loss of muscle function and mass and promote functional ability and independency in the growing population of elderly individuals.

\section{Author affiliations}

${ }^{1}$ Department of Orthopedic Surgery M, Institute of Sports Medicine Copenhagen, Bispebjerg and Frederiksberg University Hospitals, Copenhagen, Denmark

${ }^{2}$ Faculty of Health and Medical Sciences, Center for Healthy Aging, University of Copenhagen, Copenhagen, Demark

${ }^{3}$ Danish Research Centre for Magnetic Resonance, Centre for Functional and Diagnostic Imaging and Research, Copenhagen University Hospital Hvidovre, Copenhagen, Denmark

${ }^{4}$ Department of Public Health, Faculty of Health and Medical Sciences, University of Copenhagen, Copenhagen, Denmark

${ }^{5}$ Department of Physical and Occupational Therapy, Bispebjerg and Frederiksberg University Hospitals, Copenhagen, Denmark

${ }^{6}$ Department of Neurology, Bispebjerg and Frederiksberg University Hospitals, Copenhagen, Denmark

Contributors CSE, CLW and TB have made a substantial contribution to data acquisition and analysis, have drafted the manuscript and critically revised it for important intellectual content. EG, ELM, HRS and MK have made substantial contributions to conception and design of the study and critically revised the manuscript for important intellectual content. NLR has made a substantial contribution to data acquisition and analysis and has drafted the manuscript and critically revised it for important intellectual content. AKZ, ATG and KD have made a substantial contribution to data acquisition and analysis and critically revised the manuscript for important intellectual content. All authors have given final approval of the version to be published and agree to be accountable for all aspects of the work in ensuring that questions related to the accuracy or integrity of any part of the work are appropriately investigated and resolved.

Funding The initiative to the trial is taken by the authors (primarily the senior author) in relation to a donation given to Center for Healthy Aging, Faculty of Health and Medical Sciences, University of Copenhagen, which Institute of Sports Medicine Copenhagen is a part of. Center for Healthy Aging is funded by the Nordea Foundation (around US $\$ 2000000$ ), which covers payment of salary to scientific personal, running expenses as well as salary for trainers and test-leaders. Thera Band elastic bands (Akron, Ohio, USA) are used for moderate intensity training and are kindly provided by ProCare (Roskilde, Denmark). The agreement to use Thera Band elastic bands was settled after the decision to use elastic bands for the moderate intensity training.

Competing interests HRS has served on a scientific advisory board for Lundbeck A/S, Valby, Denmark; has received honoraria as speaker from Biogen Idec, Denmark A/S, Genzyme, Denmark, and Merck Serono, Denmark; has received honoraria as editor from Elsevier Publishers, Amsterdam, The Netherlands and Springer Publishing, Stuttgart, Germany; has received travel support from MagVenture, Denmark; and has received a research fund from Biogen Idec, Denmark. The other investigators declare no conflicts of interest. No funders or private companies have any influence on initiation, design, data collection and analysis, publication strategy or management of the study. A data monitoring committee is not needed since the study is investigator driven.

Ethics approval The study has been approved by the regional ethical committee (Capital Region, Copenhagen, Denmark, No. H-3-2014-017) and complies with the declaration of Helsinki. Oral and written information is provided, and oral and written consent is given before onset of data collection. Participation is entirely voluntary and participants can terminate the study at any time without questions asked and without compromising relations to the department of investigation. Changes or additions to the protocol are not implemented until approval by the ethical committee.. 
Provenance and peer review Not commissioned; externally peer reviewed.

Open Access This is an Open Access article distributed in accordance with the Creative Commons Attribution Non Commercial (CC BY-NC 4.0) license, which permits others to distribute, remix, adapt, build upon this work noncommercially, and license their derivative works on different terms, provided the original work is properly cited and the use is non-commercial. See: http:// creativecommons.org/licenses/by-nc/4.0/

\section{REFERENCES}

1. Kohl HW III, Craig CL, Lambert EV, et al. The pandemic of physical inactivity: global action for public health. Lancet 2012;380:294-305.

2. Lee IM, Shiroma EJ, Lobelo F, et al. Effect of physical inactivity on major non-communicable diseases worldwide: an analysis of burden of disease and life expectancy. Lancet 2012;380:219-29.

3. World Health Organization. Global recommendations on physical activity for health. Geneva: World Health Organization, 2010.

4. Sjöström M, Oja P, Hagströmer M, et al. Health-enhancing physical activity across European Union countries: the Eurobarometer study. J Public Health 2006;14:291-300.

5. Sun F, Norman IJ, While AE. Physical activity in older people: a systematic review. BMC Public Health 2013:13:449.

6. Hughes VA, Frontera WR, Roubenoff R, et al. Longitudinal changes in body composition in older men and women: role of body weight change and physical activity. Am J Clin Nutr 2002;76:473-81.

7. Fielding RA, Vellas B, Evans WJ, et al. Sarcopenia: an undiagnosed condition in older adults. Current consensus definition: prevalence, etiology, and consequences. International working group on sarcopenia. J Am Med Dir Assoc 2011:12:249-56.

8. Janssen I, Heymsfield SB, Wang ZM, et al. Skeletal muscle mass and distribution in 468 men and women aged 18-88 yr. J Appl Physiol 2000;89:81-8.

9. Manini TM, Clark BC. Dynapenia and aging: an update. J Gerontol A Biol Sci Med Sci 2012;67:28-40.

10. Jackson AS, Janssen I, Sui X, et al. Longitudinal changes in body composition associated with healthy ageing: men, aged 20-96 years. Br J Nutr 2012;107:1085-91.

11. Skelton DA, Greig CA, Davies JM, et al. Strength, power and related functional ability of healthy people aged 65-89 years. Age Ageing 1994;23:371-7.

12. Bassey EJ, Fiatarone MA, O'Neill EF, et al. Leg extensor power and functional performance in very old men and women. $\mathrm{Clin} \mathrm{SCl}$ 1992;82:321-7.

13. Foldvari M, Clark M, Laviolette LC, et al. Association of muscle power with functional status in community-dwelling elderly women. $J$ Gerontol A Biol Sci Med Sci 2000;55:M192-9.

14. Bean JF, Kiely DK, Herman S, et al. The relationship between leg power and physical performance in mobility-limited older people. J Am Geriatr Soc 2002:50:461-7.

15. Janssen I, Heymsfield SB, Ross R. Low relative skeletal muscle mass (sarcopenia) in older persons is associated with functional impairment and physical disability. J Am Geriatr Soc 2002;50:889-96.

16. Kortebein $\mathrm{P}$, Symons TB, Ferrando $\mathrm{A}$, et al. Functional impact of 10 days of bed rest in healthy older adults. J Gerontol A Biol Sci Med Sci 2008;63:1076-81.

17. Suetta C, Hvid LG, Justesen L, et al. Effects of aging on human skeletal muscle after immobilization and retraining. $J$ Appl Physiol 2009;107:1172-80.

18. Brown WJ, Heesch KC, Miller YD. Life events and changing physical activity patterns in women at different life stages. Ann Behav Med 2009:37:294-305.

19. Allender S, Hutchinson L, Foster C. Life-change events and participation in physical activity: a systematic review. Health Prom Int 2008;23:160-72.

20. McMunn A, Nazroo J, Wahrendorf M, et al. Participation in socially-productive activities, reciprocity and wellbeing in later life: baseline results in England. Ageing Soc 2009;29:765-82.

21. Sjosten N, Kivimaki M, Singh-Manoux A, et al. Change in physical activity and weight in relation to retirement: The French GAZEL Cohort Study. BMJ Open 2012;2:e000522.

22. Evenson KR, Rosamond WD, Cai J, et al. Influence of retirement on leisure-time physical activity: the atherosclerosis risk in communities study. Am J Epidemiol 2002;155:692-9.

23. Slingerland AS, van Lenthe FJ, Jukema JW, et al. Aging, retirement, and changes in physical activity: prospective cohort findings from the globe study. Am J Epidemiol 2007;165:1356-63.
24. Barnett I, van Sluijs EM, Ogilvie D. Physical activity and transitioning to retirement: a systematic review. Am J Prev Med 2012;43:329-36

25. Chung S, Domino ME, Stearns SC, et al. Retirement and physical activity: analyses by occupation and wealth. Am J Prev Med 2009;36:422-8.

26. Mein GK, Shipley MJ, Hillsdon M, et al. Work, retirement and physical activity: cross-sectional analyses from the Whitehall II study. Eur J Public Health 2005;15:317-22.

27. Shelton RC, McNeill LH, Puleo E, et al. The association between social factors and physical activity among low-income adults living in public housing. Am J Public Health 2011;101:2102-10.

28. Carlson JA, Sallis JF, Conway TL, et al. Interactions between psychosocial and built environment factors in explaining older adults' physical activity. Prev Med 2012;54:68-73.

29. Kouvonen A, De Vogli R, Stafford M, et al. Social support and the likelihood of maintaining and improving levels of physical activity: the Whitehall II study. Eur J Public Health 2012;22:514-8.

30. Rhodes RE, Smith NE. Personality correlates of physical activity: a review and meta-analysis. Br J Sports Med 2006;40:958-65.

31. Conn VS, Hafdahl AR, Mehr DR. Interventions to increase physical activity among healthy adults: meta-analysis of outcomes. Am J Public Health 2011;101:751-8.

32. Hillsdon M, Foster C, Thorogood M. Interventions for promoting physical activity. Cochrane Database Syst Rev 2005;(1):CD003180.

33. Hobbs N, Godfrey A, Lara J, et al. Are behavioral interventions effective in increasing physical activity at 12 to 36 months in adults aged 55 to 70 years? A systematic review and meta-analysis. BMC Med 2013;11:75.

34. Opdenacker J, Boen F, Coorevits N, et al. Effectiveness of a lifestyle intervention and a structured exercise intervention in older adults. Prev Med 2008;46:518-24.

35. Peterson MD, Rhea MR, Sen A, et al. Resistance exercise for muscular strength in older adults: a meta-analysis. Ageing Res Rev 2010;9:226-37.

36. Petersen SG, Beyer N, Hansen M, et al. Nonsteroidal anti-inflammatory drug or glucosamine reduced pain and improved muscle strength with resistance training in a randomized controlled trial of knee osteoarthritis patients. Arch Phys Med Rehabil 2011:92:1185-93

37. Liu CJ, Latham N. Can progressive resistance strength training reduce physical disability in older adults? A meta-analysis study. Disabil Rehabil 2011;33:87-97.

38. Brawley LR, Rejeski WJ, King AC. Promoting physical activity for older adults: the challenges for changing behavior. Am J Prev Med 2003;25(3 Suppl 2):172-83.

39. Fielding RA, Katula J, Miller ME, et al. Activity adherence and physical function in older adults with functional limitations. Med SCi Sports Exerc 2007;39:1997-2004.

40. Daley AJ, Maynard IW. Preferred exercise mode and affective responses in physically active adults. Psychol Sport Exerc 2003;4:347-56.

41. Kumar V, Selby A, Rankin D, et al. Age-related differences in the dose-response relationship of muscle protein synthesis to resistance exercise in young and old men. J Physiol (Lond) 2009;587:211-7.

42. Kumar V, Atherton PJ, Selby A, et al. Muscle protein synthetic responses to exercise: effects of age, volume, and intensity. J Gerontol A Biol Sci Med Sci 2012;67:1170-7.

43. Fielding RA, LeBrasseur NK, Cuoco A, et al. High-velocity resistance training increases skeletal muscle peak power in older women. J Am Geriatr Soc 2002;50:655-62.

44. Marsh AP, Miller ME, Rejeski WJ, et al. Lower extremity muscle function after strength or power training in older adults. J Aging Phys Act 2009;17:416-43.

45. Bherer L, Erickson KI, Liu-Ambrose $\mathrm{T}$. A review of the effects of physical activity and exercise on cognitive and brain functions in older adults. J Aging Res 2013;2013:657508.

46. Lautenschlager NT, Cox KL, Flicker L, et al. Effect of physical activity on cognitive function in older adults at risk for Alzheimer disease: a randomized trial. JAMA 2008;300:1027-37.

47. Lawlor DA, Hopker SW. The effectiveness of exercise as an intervention in the management of depression: systematic review and meta-regression analysis of randomised controlled trials. BMJ 2001;322:763-7.

48. Penedo FJ, Dahn JR. Exercise and well-being: a review of mental and physical health benefits associated with physical activity. Curr Opin Psychiatry 2005;18:189-93.

49. Rejeski WJ, Mihalko SL. Physical activity and quality of life in older adults. J Gerontol A Biol Sci Med Sci 2001;56 Spec No 2:23-35. 
50. King AC, Pruitt LA, Phillips W, et al. Comparative effects of two physical activity programs on measured and perceived physical functioning and other health-related quality of life outcomes in older adults. J Gerontol A Biol Sci Med Sci 2000;55:M74-83.

51. Hogstrom LJ, Westlye LT, Walhovd KB, et al. The structure of the cerebral cortex across adult life: age-related patterns of surface area, thickness, and gyrification. Cereb Cortex 2013;23:2521-30.

52. Fjell AM, Walhovd KB. Structural brain changes in aging: courses, causes and cognitive consequences. Rev Neurosci 2010;21:187-221.

53. Sexton CE, Walhovd KB, Storsve AB, et al. Accelerated changes in white matter microstructure during aging: a longitudinal diffusion tensor imaging study. J Neurosci 2014;34:15425-36.

54. Andrews-Hanna JR, Snyder AZ, Vincent JL, et al. Disruption of large-scale brain systems in advanced aging. Neuron 2007;56:924-35

55. Bennett IJ, Madden DJ. Disconnected aging: cerebral White matter integrity and age-related differences in cognition. Neuroscience 2014;276:187-205.

56. Salat $\mathrm{DH}$. The declining infrastructure of the aging brain. Brain Connect 2011;1:279-93.

57. Cotman CW, Berchtold NC, Christie LA. Exercise builds brain health: Key roles of growth factor cascades and inflammation. Trends Neurosci 2007;30:464-72.

58. Voss MW, Erickson KI, Prakash RS, et al. Neurobiological markers of exercise-related brain plasticity in older adults. Brain Behav Immun 2013;28:90-9.

59. Barnes JN. Exercise, cognitive function, and aging. Adv Physiol Educ 2015;39:55-62.

60. Erickson KI, Gildengers AG, Butters MA. Physical activity and brain plasticity in late adulthood. Dialogues Clin Neurosci 2013;15:99-108.

61. Kilgour $\mathrm{AH}$, Todd OM, Starr JM. A systematic review of the evidence that brain structure is related to muscle structure and their relationship to brain and muscle function in humans over the lifecourse. BMC Geriatr 2014;14:85.

62. Gauthier CJ, Madjar C, Desjardins-Crepeau L, et al. Age dependence of hemodynamic response characteristics in human functional magnetic resonance imaging. Neurobiol Aging 2013;34:1469-85.

63. Brown AD, McMorris CA, Longman RS, et al. Effects of cardiorespiratory fitness and cerebral blood flow on cognitive outcomes in older women. Neurobiol Aging 2010;31:2047-57.

64. Barnes JN, Taylor JL, Kluck BN, et al. Cerebrovascular reactivity is associated with maximal aerobic capacity in healthy older adults. J Appl Physiol 2013;114:1383-7.

65. Gauthier CJ, Lefort M, Mekary S, et al. Hearts and minds: linking vascular rigidity and aerobic fitness with cognitive aging. Neurobiol Aging 2015;36:304-14.

66. Oberlin LE, Verstynen TD, Burzynska AZ, et al. White matter microstructure mediates the relationship between cardiorespiratory fitness and spatial working memory in older adults. Neurolmage 2016;131:91-101.

67. Chan AW, Tetzlaff JM, Altman DG, et al. Spirit 2013 statement: defining standard protocol items for clinical trials. Ann Intern Med 2013;158:200-7.

68. American College of Sports Medicine. American College of Sports Medicine position stand. Progression models in resistance training for healthy adults. Med Sci Sports Exerc 2009;41:687.

69. Brzycki M. A practical approach to strength training. 3rd edn. Indianapolis, IN: Masters Press, 1995.

70. Gibson RS. Principles of nutritional assessment. Oxford University Press, 1990

71. Christensen $\mathrm{K}$, Thinggaard M, McGue M, et al. Perceived age as clinically useful biomarker of ageing: cohort study. BMJ 2009;339: b5262.

72. Andreoli A, Scalzo G, Masala S, et al. Body composition assessment by dual-energy X-ray absorptiometry (DXA). Radiol Med 2009;114:286-300

73. Marinangeli CP, Kassis AN. Use of dual x-ray absorptiometry to measure body mass during short- to medium-term trials of nutrition and exercise interventions. Nutr Rev 2013;71:332-42.

74. Nana A, Slater GJ, Stewart AD, et al. Methodology review: Using dual-energy x-ray absorptiometry (DXA) for the assessment of body composition in athletes and active people. Int J Sport Nutr Exerc Metab 2015;25:198-215.

75. Lund R, Mortensen EL, Christensen U, et al. Cohort profile: the Copenhagen Aging and Midlife Biobank (CAMB). Int J Epidemiol 2015.
76. Mortensen EL, Flensborg-Madsen T, Molbo D, et al. Personality in late midlife: associations with demographic factors and cognitive ability. J Aging Health 2014;26:21-36.

77. Hansen HS, Mortensen EL, Costa PT, et al. Neopi-r. Manualklinisk. Copenhagen: Dansk Psykologisk Forlag, 2004

78. Olsen LR, Mortensen EL, Bech P. Mental distress in the Danish general population. Acta Psychiatr Scand 2006;113:477-84.

79. Derogatis LR, Lipman RS, Covi L. SCL-90: an outpatient psychiatric rating scale-preliminary report. Psychopharmacol Bull 1973;9:13-28.

80. Bjorner JB, Thunedborg K, Kristensen TS, et al. The Danish SF-36 health survey: translation and preliminary validity studies. J Clin Epidemiol 1998;51:991-9.

81. Bjorner JB, Damsgaard MT, Watt T, et al. Dansk manual til SF-36: Et spørgeskema om helbredsstatus. Copenhagen: Lif, 1997.

82. Washburn RA, Smith KW, Jette AM, et al. The Physical Activity Scale for the Elderly (PASE): development and evaluation. J Clin Epidemiol 1993;46:153-62.

83. Marcus BH, Selby VC, Niaura RS, et al. Self-efficacy and the stages of exercise behavior change. Res $Q$ Exerc Sport 1992:63:60-6.

84. Bandura A. The explanatory and predictive scope of self-efficacy theory. J Soc Clin Psychol 1986;4:359-73.

85. Yardley L, Donovan-Hall M, Francis K, et al. Attitudes and beliefs that predict older people's intention to undertake strength and balance training. J Gerontol B Psychol Sci Soc Sci 2007;62: P119-25.

86. Ajzen I. The theory of planned behavior. Organ Behav Hum Decis Process 1991:50:179-211.

87. Holden MA, Haywood KL, Potia TA, et al. Recommendations for exercise adherence measures in musculoskeletal settings: a systematic review and consensus meeting (protocol). Syst Rev 2014;3:10

88. Simonsick EM, Fan E, Fleg JL. Estimating cardiorespiratory fitness in well-functioning older adults: treadmill validation of the long distance corridor walk. J Am Geriatr Soc 2006;54:127-32.

89. Pettee Gabriel KK, Rankin RL, Lee C, et al. Test-retest reliability and validity of the 400-meter walk test in healthy, middle-aged women. J Phys Act Health 2010;7:649-57.

90. Bassey EJ, Short AH. A new method for measuring power output in a single leg extension: feasibility, reliability and validity. Eur $J \mathrm{Appl}$ Physiol Occup Physiol 1990;60:385-90.

91. Bieler T, Magnusson SP, Kjaer M, et al. Intra-rater reliability and agreement of muscle strength, power and functional performance measures in patients with hip osteoarthritis. J Rehabil Med 2014;46:997-1005.

92. Jones CJ, Rikli RE, Beam WC. A 30-s chair-stand test as a measure of lower body strength in community-residing older adults. Res Q Exerc Sport 1999;70:113-9.

93. Roberts $\mathrm{HC}$, Denison $\mathrm{HJ}$, Martin $\mathrm{HJ}$, et al. A review of the measurement of grip strength in clinical and epidemiological studies: towards a standardised approach. Age Ageing 2011;40:423-9.

94. Wang CY, Chen LY. Grip strength in older adults: test-retest reliability and cutoff for subjective weakness of using the hands in heavy tasks. Arch Phys Med Rehabil 2010;91:1747-51.

95. Liepmann D. Intelligenz-struktur-test 2000 r: Ist 2000 r: Hogrefe, 2007.

96. Skelton DA, Young A, Greig CA, et al. Effects of resistance training on strength, power, and selected functional abilities of women aged 75 and older. J Am Geriatr Soc 1995;43:1081-7.

97. Capodaglio P, Capodaglio Edda M, Facioli M, et al. Long-term strength training for community-dwelling people over 75: impact on muscle function, functional ability and life style. Eur J Appl Physiol 2007; 100:535-42.

98. Henwood TR, Riek S, Taaffe DR. Strength versus muscle power-specific resistance training in community-dwelling older adults. J Gerontol A Biol Sci Med Sci 2008;63:83-91.

99. Reid KF, Callahan DM, Carabello RJ, et al. Lower extremity power training in elderly subjects with mobility limitations: a randomized controlled trial. Aging Clin Exp Res 2008;20:337-43.

100. Kirn DR, Reid KF, Hau C, et al. What is a clinically meaningful improvement in leg-extensor power for mobility-limited older adults? J Gerontol A Biol Sci Med Sci 2016;71:632-6.

101. Byrnes WC, Clarkson PM. Delayed onset muscle soreness and training. Clin Sports Med 1986;5:605-14. 